\title{
Assessing the Structural and Concurrent Validity of a Shortened Version of the Domestic Violence Healthcare Providers' Survey Questionnaire for Use in Sweden
}

\author{
Stephen Lawoko ${ }^{1 *}$, Sören Sanz ${ }^{2}$, Lotti Helström ${ }^{3}$, Maaret Castren ${ }^{3}$ \\ ${ }^{1}$ Department of Public Health Sciences, Karolinska Institute, Stockholm, Sweden \\ ${ }^{2}$ Department of Emergency Medicine, Södersjukhuset, Stockholm, Sweden \\ ${ }^{3}$ Department of Clinical Science and Education, Karolinska Institute, Stockholm, Sweden \\ Email: "stephen.lawoko@ki.se
}

Received November $21^{\text {st }}$, 2011; revised December 29 ${ }^{\text {th }}$, 2011; accepted January $28^{\text {th }}, 2012$

\begin{abstract}
Background: It has recently become incumbent on researchers to develop tools for the assessment of healthcare practitioners' readiness to screen for Intimate Partner Violence (IPV). One such comprehensive tool is the Healthcare Provider Survey Scales (DVHPSS). Its usefulness in new settings however warrants a validity test. Aim: We assessed some aspects of the structural validity of a shortened version of the DVHPSS. Method: Health care workers at a health facility in Sweden $(n=193)$ responded to a shortened version of the DVHPSS. Exploratory factor analysis, Cronbach's Alpha, correlation, T-test, and ANOVA were used to analyse the data. Criteria for inclusion were set a priori. Results: All items of the shortened DVHPSS were retained following analysis. A six factor model emerged, with slight modifications of the original scales. Concurrent validity of the emerging scales was confirmed. Conclusions: The DVHPSS is a valid tool to assess readiness to screen for IPV in Swedish healthcare.
\end{abstract}

Keywords: Domestic Violence Survey; Structural Validity; Healthcare Providers; Sweden

\section{Introduction}

Intimate Partner Violence (IPV) against women has long been recognised as a public health problem considering its social and health implications. When contrasted with women living in non-violent intimate relationships, abused women to a higher degree report injuries that range in severity from bruises to fractured bones following physical assaults (Aimakhu, Olayemi, Iwe, Oluyemi, Ojoko, Shoretire, Adeniji, \& Aimakhu, 2004; Koenig, Ahmed, Hossain, \& Khorshed, 2003; Fawole, Aderonmu, \& Fawole, 2005), evidence reproductive health problems including terminated pregnancies, undesired pregnancies and child loss during infancy (Garcia-Morena, Jansen, Ellsberg, Heise, \& Watts, 2005; Kishor \& Johnson, 2004), exhibit psychosocial manifestations of depression, anxiety and post-traumatic stress disorder and adopt health risk behaviours such as unhealthy feeding habits, substance abuse, alcoholism and suicidal behaviours (Koss, 1990; Heise \& Garcia-Moreno, 2002; Tjaden \& Thoennes, 2000; Tolman \& Rosen, 2001; Petersen, Gazmararian, \& Clark, 2001).

Despite the higher likelihood for morbidity, women experiencing IPV when contrasted with non-abused peers, tend to use community and healthcare services more sparingly and exhibit restraint towards bonding with healthcare providers and employers (Heise \& Garcia-Moreno, 2002; Petersen, Gazmararian, \& Clark, 2001). A recent WHO multi-country study of 10 countries including low, middle and high income countries, (WHO, 2005) found fear of retaliation from the abuser, stigmatizing attitudes from service providers and community at large to hinder abused women from seeking sanctuary from formal ${ }^{*}$ Corresponding author. networks (e.g. healthcare). They were however more prone to report abuse to the informal networks (e.g. family and relatives). A recent Swedish study indicated that trust in the judiciary among abused women was low and that few abused women (25\%) are offered assistance from relevant formal institutions (BRÅ rapport 2009). Overall, these findings suggest that victims of IPV may be prone to social and institutional marginalisation or that formal institutions are inadequately equipped to assist IPV victims. The healthcare system thus could play an important role to reverse this notion through the institutional detection and management of IPV enhanced by screening for the phenomena among women visiting healthcare settings.

Over the past decade, a number of instruments to assist healthcare providers in screening for IPV have been developed, particularly in Europe and America (Feldhaus, Kozio-Mclain, Amsbury, Norton, Lowenstein, \& Abbott, 1997; McFarlane, Parker, Soeken, \& Bullock, 1992; Sohal, Eldridge, \& Feder, 2007). Despite these developments, barely one in ten healthcare providers screen for IPV evidencing barriers to such screening (Roelens, Verstraelen, Van Egmond, \& Temmerman, 2006; Erikson, Hill, \& Siegal, 2001). These barriers may evolve from structural factors inherent in care provision, healthcare provider characteristics as well as characteristics incumbent in the recipient of care (i.e. patients/clients). Together, such factors could influence providers' readiness to screen for IPV as well as consumers' acceptance for being probed on IPV. In this paper, emphasis is laid on the former.

A few instruments are available to researchers for the assessment of providers' readiness to screen for IPV (Short, Alpert, Harris, \& Surprenant, 2006; Rodríguez, Bauer, McLoughlin, \& Grumbach, 1999). Among the most comprehensive of 
them is the Domestic Violence Healthcare Provider Survey Scales (DVHPSS) (Maiuro, Vitaliano, Sugg, Thompson, Rivara, \& Thompson, 2000). The scale measures healthcare professionals' readiness to screen in terms of their perceived knowledge, efficacy in screening, conflicting professional roles, availability of social support networks to which IPV victims can be referred, client safety challenges that IPV inquiries could impose, and providers' general attitudes towards screening for IPV. Though the DVHPSS has been validated in some countries (e.g. USA and Nigeria) its usefulness in other societal contexts is yet to be verified. This study sets the foundation to fill this knowledge gap by validating the DVHPSS before it can be used in the future assessment of planned programs to screen for IPV in healthcare Sweden.

Validity is an important issue when using abstract measures/questions to represent theoretical concepts. In very general terms, an instrument is said to be valid when it measures what it is supposed to measure (Nunnaly, 1978). Structural validity is an important aspect of validity. It comprises primarily the factorial structure of an instrument and its reliability. Factorial structure attempts to identify which underlying concepts a set of questions/items/variables may be capturing, without imposing a preconceived structure on what these questions are measuring. When measuring readiness to screen for IPV therefore, one may be interested in understanding the detailed structures/concepts that may emerge given a set of variables/items purported to measure readiness as a whole.

Reliability refers to the accuracy and precision of a measurement procedure or instrument (Thorndike, Cunningham, Thorndike, \& Hagen, 1991). It answers the question of how well an instrument measures what it is purported to measure. Internal consistency is one form of reliability measure which assesses individuals performance from item to item when data is collected using a single form (Cronbach \& Meehl, 1995). The rationale behind internal consistency is that items assumed to represent a specific sub-scale (concept) will exhibit high correlations with each other on average. A low/non-significant correlation evidences low reliability. It is based on this rationale that sub-scales are tested for reliability. In this study, the concepts that emerge from the factor analysis are tested for reliability.

Concurrent validity refers to an instruments ability to distinguish between groups hypothesised to differ in the measurement in question (Nunnaly, 1978). For instance, it may be hypothesised that female care providers are more prone than male peers to inquire about IPV as they are more likely to identify with the problem, being potential victims; nurses/midwives may be more prone to inquire about IPV as they are more often at the forefront of care provision for women; experienced personal may be more likely to probe for IPV etc. Indeed, prior studies have suggested differences in readiness to screen depending on gender, staff cadre, training and experience (Maiuro, Vitaliano, Sugg, Thompson, Rivara, \& Thompson, 2000).

The rationale of testing the validity of readiness to screen instruments before use in new contexts/populations cannot be overemphasised as an important area of Public health research. Healthcare systems vary in their structure and so do providers in their training and attitudes from one context to another. The structure of readiness to screen for IPV indicators could therefore vary between dissimilar populations. Indeed, it has long been emphasised that the psychometric properties of any instrument need an assessment in new populations before their use in explanatory modelling (e.g. to examine theoretical rela- tionships with other constructs, study predictors of outcome variables and in assessment of interventions impact on particular outcome measures) (Cronbach \& Meehl, 1995). It is on this basis that the structural validity of the Domestic Violence Healthcare Provider Survey Scales (DVHPSS) is tested in Sweden for the first time in this study, for later use in evaluation of training programmes aimed at promoting IPV screening in Swedish healthcare facilities. Moreover, an extension of the application of the DVHSS to new settings will enhance the development of internationally comparable database to assess and compare efforts towards IPV screening on a global front.

The objective of this study thus is to assess the structural validity of the DVHPSS in terms of its factorial structure, subscale reliability and concurrent validity. More concretely, the following research questions are addressed:

1) Do the questions of the DVHPSS capture adequately the underlying constructs they are purported to measure when applied in the Swedish healthcare context (i.e. the question of factorial stability)?

2) Do Swedish care providers identify with/respond consistently to the questions of the DVHPSS (i.e. the question of internal consistent/reliability)?

3) Does the DVHPSS distinguish between different categories (e.g. cadres) of healthcare workers hypothesised to differ in readiness to screen (i.e. concurrent validity)?

\section{Methods}

\section{Study Settings, Design and Participants}

This study was carried out among healthcare providers at the emergency clinic, women's clinic and ambulatory services at the Södersjukhuset, Sweden, which is one of the largest multidepartmental hospitals in the country. The healthcare providers at the hospital have not previously undergone any formal training in screening for IPV among their female clients. This study undertakes to assess the validity of an instrument that could be used to assess readiness to screen at the hospital, and to inform training needs for eventual screening.

A total of 193 providers participated. Table 1 provides information regarding demographic and occupational distribution of the participants. Convenient sampling was used to arrive at this figure. The questionnaire was available to all staff members online and was left there until an optimal sample size to run a structural validity test was reached (for about 30 items you need at least 3 times as many participants to run a factor analysis). Also, to run a concurrent validity a common approach (Altman, 1991; Altman, 1982) that takes into account the level of precision (set by the authors at plus/minus $4 \%$ ), the level of statistical significance to be assumed (by convention usually 95\% confidence interval), the total number of number in the population (in this case the total number of care providers working at the study departments during that period i.e. approximately $n=$ 800) and the expected prevalence of screening (estimated at $10 \%$ from previous studies (Erikson et al., 2001; Roelens, Verstraelen, Van Egmond, \& Temmerman, 2006)). These conditions would give an optimal sample size of approximately $n=$ 170. We opted for 217 but 193 of these responded to the questions relevant for this study.

All employees at the above mentioned departments were offered the opportunity to participate in this study through a web survey accessible to all employees who visit the internal hospi- 
Table 1.

Demographic and occupational characteristics of participants responding to all DVHSS scales.

\begin{tabular}{cll}
\hline & n & $\%$ \\
\hline Gender & 39 & 21 \\
Male & 154 & 79 \\
Female & & \\
Staff Cadre & 29 & 16 \\
Doctor & 71 & 40 \\
Nurse & 44 & 24 \\
Nursing Assistant & 27 & 15 \\
Midwife & 8 & 5 \\
Other & & \\
Department & 125 & 67 \\
Emergency & 49 & 26 \\
Women's Clinic & 12 & 71 years (11.2 years) \\
Ambulatory & Age &
\end{tabular}

$\mathrm{n}$ = number within category; $\%$ = proportion within category.

tal employee website. The survey was available on the website during the period June-August of 2009. Information of the study was given by the respective department heads and further emphasised on the website. Voluntary participation was emphasised and informed consent given. The study design was cross-sectional.

\section{Ethical Consideration}

This study received ethical approval from the regional ethical review board. The aims and relevance of the study were explained to the participants and information on the same offered on the web. Voluntary participation was emphasised, privacy guaranteed and informed consent given. Participants' responses were anonymous.

\section{Instrument Measures in Original Format}

The Domestic Violence Health Care Provider Survey Scale measures healthcare providers' readiness to screen for IPV as well as actual screening activity (Maiuro, Vitaliano, Sugg, Thompson, Rivara, \& Thompson, 2000). The instrument has been previously validated with promising results in some countries including USA and Nigeria. The questionnaire, in its original format, is composed of the following 5 subscales:

The perceived self efficacy subscale scale (4 items) assesses providers own perceived efficacy in inquiring about IPV (details in Table 2).

The system support sub-scale (4 items) assesses healthcare providers' access to support networks for referral/management of IPV victims (details in Table 2).

The professional roles resistant/fear of offending clients sub-scale (6 items) assesses whether providers perceive inquiries about IPV may conflict with ethical issues governing their communication with clients (details in Table 2).

The blame victim sub-scale (7 items), assesses providers attitudes towards victims (details in Table 2).

The victim/provider safety sub-scale (10 items), assesses whether providers perceive inquiries about IPV from batterers to further jeopardize safety of victims and/or care provider (these items are not used in this study as they are not applicable to providers at the current setting).

All items require of the respondent to take a position on specific statements. The response alternatives to each statement range from 1 (strongly disagree) to 5 (strongly agree).

\section{Instrument Re-Adaptation to Swedish Setting}

The entire questionnaire was first translated to the Swedish language (the official language in the country) by a professional translator. Another independent translator with good knowledge of both languages then translated the Swedish translation back to English. The authors (who understand both languages) then studied and scrutinised the translation and agreed to adopt it with minor modifications. The team however also scrutinised the content of all 35 questions and their applicability in the studied setting. All questions relating to probing about IPV from the potential perpetrators were excluded from this study, as the hospital leadership indicated that their organisation intends to introduce a screening protocol that exclusively probes of IPV possibility only among potential victims. A crucial and first step in validity assessment is that the questions should appear relevant to the participants in question. The research team acknowledged thus that including questions that the participants would not identify with was likely to affect negatively the overall validity of the questionnaire. A total of 13 questions were therefore excluded from the web-survey. Thus, this work scrutinizes the validity of a shortened version of the DVHSS.

\section{Statistical Analysis}

Data cleansing: Prior to analyses, certain procedures were carried out to clean data. First, only participants who had responded to all items of the DVHSS were included in the analyses above to reduce the likelihood of erroneous estimates as a result of missing data. Second, items were checked for normality using the skewness statistic and its confidence interval. Skewness statistic of magnitude zero is an indication of perfect symmetry. Relevant transformations (e.g. square roots, logarithm, inverse or reflection) were applied to transform skewed data.

Factor analysis and reliability test: An exploratory factor analysis (instead of a confirmatory one) was preferred. The advantage of such an analysis is that it does not take a preconceived position on which questions should be included under each sub-scale. It is plausible that certain questions could in another context merge or split to form new sub-scales. Thus, exploratory factor analysis using principal component method was performed to test underlying factors and their stability as expressed in the factor loadings. Varimax rotation was applied to limit the number of high loadings under the same factor. This would enhance clearer identification of items emerging under 
Table 2.

Rotated factor loadings of the items of the shortened domestic violence healthcare providers survey scales restricted to 6 factors.

\begin{tabular}{|c|c|c|c|c|c|c|}
\hline Components & 1 & 2 & 3 & 4 & 5 & 6 \\
\hline \multicolumn{7}{|l|}{ Factor 1: Perceived self-efficacy } \\
\hline I have no time to ask about IPV in my practice. & 0.398 & 0.271 & -0.020 & 0.270 & 0.288 & 0.036 \\
\hline There are strategies I can use to help victims of IPV change their situation. & -0.724 & -0.147 & -0.080 & 0.010 & 0.347 & -0.079 \\
\hline I feel confident that I can make the appropriate referrals for abused patients. & 0.767 & 0.276 & -0.104 & -0.029 & -0.080 & -0.037 \\
\hline I have ready access to information detailing management of IPV. & -0.848 & 0.003 & 0.008 & -0.071 & 0.083 & -0.074 \\
\hline $\begin{array}{l}\text { I have ready access to medical social workers or community } \\
\text { advocates to assist in the management of IPV. }\end{array}$ & 0.778 & -0.025 & -0.065 & 0.060 & 0.227 & 0.137 \\
\hline I feel that medical social work personnel can help manage IPV patients. & 0.661 & -0.046 & 0.036 & 0.092 & 0.237 & 0.203 \\
\hline \multicolumn{7}{|l|}{ Factor 2: Fear of offending patients } \\
\hline I am afraid of offending the patient if I ask about IPV. & 0.251 & 0.658 & 0.128 & 0.077 & 0.093 & 0.072 \\
\hline Asking patients about IPV is an invasion of their privacy. & 0.119 & 0.850 & 0.170 & 0.055 & -0.158 & 0.012 \\
\hline It is demeaning to patients to question them about abuse. & 0.044 & 0.808 & 0.022 & 0.132 & 0.118 & -0.002 \\
\hline If I ask non-abused patients about IPV, they will get very angry. & -0.117 & 0.532 & -0.077 & 0.270 & 0.240 & 0.018 \\
\hline \multicolumn{7}{|l|}{ Factor 3: Victim personality/trait } \\
\hline $\begin{array}{l}\text { A victim must be getting something out of the abusive relationship, } \\
\text { or else he/she would leave. }\end{array}$ & 0.125 & -0.013 & -0.655 & -0.115 & -0.263 & -0.229 \\
\hline People are only victims if they choose to be. & 0.005 & 0.019 & 0.704 & 0.078 & 0.069 & 0.048 \\
\hline $\begin{array}{l}\text { When it comes to domestic violence victimization, it usually } \\
\text { takes two to tango. }\end{array}$ & 0.060 & 0.034 & 0.639 & 0.151 & -0.083 & -0.191 \\
\hline I have patients whose personalities cause them to be abused. & -0.069 & 0.100 & 0.523 & -0.116 & 0.322 & -0.175 \\
\hline The victim's passive-dependent personality often leads to abuse. & -0.118 & 0.283 & 0.502 & -0.147 & 0.366 & -0.176 \\
\hline \multicolumn{7}{|l|}{ Factor 4: Professional role resistance } \\
\hline It is not my place to interfere with how a couple chooses to resolve conflicts. & 0.083 & 0.283 & 0.429 & 0.545 & -0.162 & -0.204 \\
\hline Investigating the cause of IPV is not part of medical practice. & 0.086 & 0.094 & -0.045 & 0.797 & 0.161 & -0.122 \\
\hline If patients do not reveal abuse to me, then they feel it is none of my business. & 0.046 & 0.280 & 0.294 & 0.673 & -0.041 & 0.181 \\
\hline \multicolumn{7}{|l|}{ Factor 5: Victim disobedience } \\
\hline Women who choose to step out of traditional roles are a major cause of IPV. & 0.069 & 0.154 & 0.266 & 0.025 & 0.672 & -0.011 \\
\hline The victim has often done something to bring about violence in the relationship. & 0.063 & -0.021 & 0.395 & 0.243 & 0.452 & -0.179 \\
\hline \multicolumn{7}{|l|}{ Factor 6: Psychiatric support } \\
\hline I have ready access to mental health services should our patients need referrals. & 0.428 & 0.041 & -0.063 & -0.119 & -0.047 & 0.619 \\
\hline $\begin{array}{l}\text { I feel that the mental health services at my clinic or agency can } \\
\text { meet the needs to IPV victims in cases where they are needed. }\end{array}$ & 0.129 & 0.056 & -0.096 & 0.001 & -0.075 & 0.850 \\
\hline Eigenvalues & 4.27 & 3.52 & 1.78 & 1.28 & 1.12 & 1.06 \\
\hline$\%$ of Variance & 19.39 & 16.02 & 8.20 & 5.82 & 5.10 & 4.83 \\
\hline
\end{tabular}

Note: Factors loading over 0.30 appear in bold. The extraction method used was principal component Analysis and rotation method: Varimax rotation with Kaiser Normalization (eigenvalues $>1$ ).

each subscale. Criteria for the number of resulting significant factors was based on Kaiser Criterion and confirmed with scree plots (Carrol, 1957; Field, Aneja, \& Rosner, 2007). Items with factor loading of at least 0.30 were considered significant; this is based on criteria for significant correlation (Cohen, 1988). The contribution of each factor in explaining the total variation in the item pool was reported. Significant factors (i.e. those having a highest loading of over 0.30) were tested for internal consistency using Cronbach's Alpha. Each item was then scrutinised further to assess whether the removal of that item would improve the alpha coefficient. If removal of an item implied improved alpha, that item would be removed and the reliability test re-run without that item. The process would continue until a point of saturation was reached (i.e. removal of additional items would not improve alpha). Alpha coefficients of at least 0.70 were considered significant, a threshold adequate for research purposes (Streiner \& Norman, 1989; Nunnaly, 1978). However, for scales with only two items, a lower threshold (i.e. 0.30 ) was considered modest, as this is the boundary set for significant bivariate correlation (Cohen, 1988). The resulting items/scales following the reliability test were then re-examined in a new factor analysis. If any of the highest item loadings was less than 0.30 , the process described above (i.e. series of factor analyses and reliability test) would continue until all remaining items loaded at least 0.30 , the a priori set threshold. Where double loadings were evident, the item was assigned to the 
factor under which it loaded highest.

Scale distinctiveness: Bivariate correlations were run to investigate factor distinctiveness of the final factor solution (Streiner \& Norman, 1989; Nunnaly, 1978).

Testing for concurrent validity/sensitivity: The individual means on the emerging sub-scales (obtained via factor analysis and reliability tests described above) were calculated so as to assess for differences between groups hypothesised to differ in such scores (concurrent validity). The distribution of the individual means on sub-scales followed a normal distribution. Thus, T-test, Analysis of Variance (ANOVA) (with benferroni adjustment for multiple pairwise comparison) and bivariate correlations were run to test for hypothesised differences in scores (means, range 1 - 5) by gender, age, staff cadre, department and experience.

\section{Results}

\section{Data Cleansing}

Of the 217 respondents, a total of 193 participants (i.e. 89\%) had completed all questions of the DVHSS. Responses to most of the questions followed a skewed distribution. Relevant transformations e.g. logarithm, square roots and inverses were therefore made to transform non-normal data.

\section{Initial Factorial Structure with All Items}

When all items of the original scales (in their transformed or original format) were included in the factor analysis, 6 factors emerged based on the Kaiser Criterion (Eigen values $>1$ ) (Table 2). All items of the shortened DVHPSS exhibited significant factor loading according to the apriori decided threshold of at least 0.30 (Table 2).

Factor 1 emerged as the perceived self-efficacy subscale with all items of the original scale loading significantly under this factor. This six-itemed subscale explained $19.3 \%$ of the variation in the total item pool.

Factor 2 emerged as fear of offending patient subscale, a split of the original merger between professional role resistance/fear of offending clients subscale. This 4-itemed subscale explained $16 \%$ of the variation in the total item pool. The remaining items of the original scale loaded under factor 4 , a professional role resistant subscale. This 3 -itemed subscale explained $5.8 \%$ of the variation in the total item pool.

Factor 3 reflected a victim personality/trait component, with 5 items resulting from a split of the original blame the victim scale which comprised 7 items. The other two items emerged as factor 5 reflecting a victim disobedience aspect. Factor 3 explained $8 \%$ while factor 5 explained $5 \%$ variation in the total item pool.

Factor 6 reflected a psychiatric support component with two out of four of the original items loading heavily under this factor. The factor explained $4.8 \%$ of the variation in the total item pool.

\section{Internal Reliability}

As all items loaded significantly (with highest loadings of 0.30 and above) under specific factors, the items included under each factor were subjected to reliability test. As indicated in Table 3, the internal reliability of the 6-itemed perceived self-efficacy subscale was 0.71 . Though removal of the item "I do not have time to ask about DV in my practice" could enhance reliability to 0.83 , we choose not to remove this item as the reliability coefficient with it present met the apriori decided threshold (i.e. 0.70 or higher). In addition, the internal reliability of the 4-itemed fear of offending patient subscale was 0.76 . Removal of additional items was therefore not necessary and would not improve the internal consistency. The internal reliability of the 5 itemed victim personality/trait subscale was 0.63. Removal of additional items would not improve the internal consistency. The internal reliability of the 3-itemed professional role resistant subscale was 0.57 . Removal of additional items from this scale would only reduce the internal reliability. The internal reliability of the 2-itemed victim disobedience subscale was 0.38 . Finally, the internal reliability of the 2 itemed of the psychiatric support subscale was 0.60 .

In total therefore, the reliability test did not drop any items based on apriori decided criteria.

\section{Inter-Factor Correlation}

As indicated by the bivariate correlations in Table 4, significant correlations ranging in magnitude between 0.17 and 0.52 were found between many of the factors.

\section{Testing for Concurrent Validity/Sensitivity}

As indicated in Table 5, male care providers were more likely than female peers to perceive that victim personality ( $p<$ $0.05)$ and victim disobedience $(p<0.001)$ triggered abuse of women. In addition, male providers perceived that screening for IPV conflicted with professional roles to a higher degree than female peers $(p<0.01)$.

Staff cadres differed significantly in readiness to screen with regard to self-efficacy ( $p<0.001)$, perceptions of victims personality as a cause of abuse $(p<0.01)$ and availability of psychiatric support $(p<0.01)$ (Table 5). Midwives on average graded a lower self-efficacy in probing for IPV than all staff cadre categories studied ( $p<0.05$ for all pairwise comparisons), but were less likely to endorse that victim personality was the cause of abuse when contrasted with nursing assistants ( $p<$ 0.05 ). On the other hand, nursing assistants perceived on average higher access to psychiatric support than midwives $(p<0.05)$.

Departments differed significantly on readiness to screen for IPV with regard to self-efficacy ( $p<0.001$ ), fear of offending clients $(p<0.05)$ and perceptions that victim disobedience was the cause of IPV $(p<0.01)$. The emergency department perceived a higher efficacy when contrasted with women's clinic $(p<0.05)$ and ambulatory department $(p<0.05)$. On the other hand, the ambulatory department were more fearful of offending clients with regard to IPV inquiry than peers in emergency $(p<0.05)$ and women's clinics $(p<0.05)$. They were also more likely to perceive that victim disobedience was the cause of IPV than peers in emergency $(p<0.05)$ and women's clinics $(p<$ $0.05)$.

Significant correlation was observed between age/experience and some indicators of readiness to screen. With increasing age, care providers perceived increasing efficacy in handling IPV against women $(p<0.05)$ and decreasing fear of offending clients $(p<0.05)$. Similarly, with increasing working experience care providers perceived increasing efficacy in handling IPV against women $(p<0.05)$ and decreasing fear of offending clients $(p<0.05)$. 
Table 3.

Internal consistency of items of the shortened domestic violence healthcare provider survey.

\begin{tabular}{|c|c|c|}
\hline Components & Cronbach alpha & Cronbachs alpha if item removed \\
\hline Factor 1: Perceived self-efficacy & 0.71 & \\
\hline I have no time to ask about IPV in my practice. & & 0.83 \\
\hline There are strategies I can use to help victims of IPV change their situation. & & 0.62 \\
\hline I feel confident that I can make the appropriate referrals for abused patients. & & 0.61 \\
\hline I have ready access to information detailing management of IPV. & & 0.58 \\
\hline $\begin{array}{l}\text { I have ready access to medical social workers or community advocates } \\
\text { to assist in the management of IPV. }\end{array}$ & & 0.60 \\
\hline I feel that medical social work personnel can help manage IPV patients. & & 0.66 \\
\hline Factor 2: Fear of offending patients & 0.76 & \\
\hline I am afraid of offending the patient if I ask about IPV. & & 0.73 \\
\hline Asking patients about IPV is an invasion of their privacy. & & 0.65 \\
\hline It is demeaning to patients to question them about abuse. & & 0.66 \\
\hline If I ask non-abused patients about IPV, they will get very angry. & & 0.75 \\
\hline Factor 3: Victim personality/trait & 0.63 & \\
\hline $\begin{array}{l}\text { A victim must be getting something out of the abusive relationship, } \\
\text { or else he/she would leave. }\end{array}$ & & 0.52 \\
\hline People are only victims if they choose to be. & & 0.55 \\
\hline When it comes to domestic violence victimization, it usually takes two to tango. & & 0.62 \\
\hline I have patients whose personalities cause them to be abused. & & 0.56 \\
\hline The victim's passive-dependent personality often leads to abuse. & & 0.54 \\
\hline Factor 4: Professional role resistance & 0.57 & \\
\hline It is not my place to interfere with how a couple chooses to resolve conflicts. & & 0.42 \\
\hline Investigating the cause of IPV is not part of medical practice. & & 0.56 \\
\hline If patients do not reveal abuse to me, then they feel it is none of my business. & & 0.41 \\
\hline Factor 5: Victim disobedience & 0.38 & \\
\hline Women who choose to step out of traditional roles are a major cause of IPV. & & na \\
\hline The victim has often done something to bring about violence in the relationship. & & na \\
\hline Factor 6: Psychiatric support & 0.60 & \\
\hline I have ready access to mental health services should our patients need referrals. & & na \\
\hline $\begin{array}{l}\text { I feel that the mental health services at my clinic or agency can meet the } \\
\text { needs to IPV victims in cases where they are needed. }\end{array}$ & & na \\
\hline
\end{tabular}

Table 4.

Bivariate pearson correlations between scales of the shortened domestic violence healthcare provider survey tool.

\begin{tabular}{|c|c|c|c|c|c|}
\hline & Self-efficacy & Fear of offending clients & Victim personality & Professional roles & Victim disobedience \\
\hline Self-efficacy & & & & & \\
\hline Fear of offending clients & $-0.17^{*}$ & & & & \\
\hline Victim personality & 0.12 & $0.22^{* *}$ & & & \\
\hline Professional roles & -0.08 & $0.44^{* *}$ & $0.28^{* *}$ & & \\
\hline Victim disobedience & -0.02 & $0.23^{* *}$ & $0.52^{* *}$ & $0.31^{* *}$ & \\
\hline Psychiatric support & $0.43^{* *}$ & -0.07 & $0.23^{* *}$ & 0.07 & 0.14 \\
\hline
\end{tabular}

\section{Discussion}

The factorial structure, internal reliability and sensitivity of a shortened version of the Domestic Violence Healthcare Provider Survey Scales (DVHPSS) in a sample of Swedish healthcare providers were tested based on apriori defined criteria. These criteria are in line with recommendations for assessment of structural validity (Streiner \& Norman, 1989; Nunnaly, 1978; Carrol, 1957; Field, Aneja, \& Rosner, 2007; Cohen, 1988). The analysis was thus designed so as to maintain only items and factors that met these criteria. None of the items where dropped following the criteria set, suggesting that the current Swedish sample identified with the questions. However, though many of the emerging concepts from this analysis were congruent with those of the original instrument, there were some notable distinctions discussed in the following text.

All items reflecting self efficacy in the original scale loaded under factor 1 in our study, but an additional two items from 
Table 5.

Differences in DVHSS sub-scales by gender, staff cadre, department, age and experience: assessing concurrent validity.

\begin{tabular}{|c|c|c|c|c|c|c|}
\hline & Self-efficacy ${ }^{*}$ & $\begin{array}{l}\text { Fear of offending } \\
\text { clients }^{*}\end{array}$ & $\begin{array}{l}\text { Blame victim } \\
\text { personality }^{*}\end{array}$ & $\begin{array}{l}\text { Victim } \\
\text { disobedience }^{*}\end{array}$ & $\begin{array}{l}\text { Psychiatric } \\
\text { support }^{*}\end{array}$ & $\begin{array}{l}\text { Professional role } \\
\text { conflict }^{*}\end{array}$ \\
\hline & Mean (S.E) & Mean (S.E) & Mean (S.E) & Mean (S.E) & Mean (S.E) & Mean (S.E) \\
\hline \multicolumn{7}{|l|}{ Gender } \\
\hline Male & $3.52(0.16)$ & $1.88(0.11)$ & $2.05(0.14)$ & $1.47(0.09)$ & $2.76(0.15)$ & $1.73(0.12)$ \\
\hline Female & $3.65(0.07)$ & $1.66(0.05)$ & $1.73(0.05)$ & $1.15(0.03)$ & $2.70(0.08)$ & $1.41(0.04)$ \\
\hline \multicolumn{7}{|l|}{ Staff cadre } \\
\hline Doctor & $3.84(0.16)$ & $1.49(0.09)$ & $1.95(0.12)$ & $1.19(0.09)$ & $2.77(0.22)$ & $1.58(0.12)$ \\
\hline Nurse & $3.82(0.07)$ & $1.83(0.08)$ & $1.71(0.08)$ & $1.14(0.04)$ & $2.62(0.13)$ & $1.50(0.07)$ \\
\hline Nursing assistant & $3.91(0.13)$ & $1.63(0.09)$ & $2.07(0.12)$ & $1.33(0.08)$ & $3.10(0.17)$ & $1.40(0.07)$ \\
\hline Midwife & $2.83(0.14)$ & $1.62(0.15)$ & $1.44(0.10)$ & $1.11(0.08)$ & $2.24(0.14)$ & $1.28(0.10)$ \\
\hline Other & $4.39(0.20)$ & $1.25(0.08)$ & $1.80(0.12)$ & $1.25(0.09)$ & $3.56(0.15)$ & $1.29(0.16)$ \\
\hline \multicolumn{7}{|l|}{ Department } \\
\hline Women's clinic & $3.16(0.13)$ & $1.65(0.10)$ & $1.64(0.09)$ & $1.13(0.06)$ & $2.55(0.16)$ & $1.37(0.08)$ \\
\hline Emergency & $3.88(0.06)$ & $1.70(0.06)$ & $1.85(0.06)$ & $1.20(0.03)$ & $2.78(0.09)$ & $1.49(0.05)$ \\
\hline Ambulatory & $2.15(0.14)$ & $2.22(0.13)$ & $1.73(0.15)$ & $1.62(0.22)$ & $2.08(0.12)$ & $1.80(0.20)$ \\
\hline $\begin{array}{c}\text { Age } \\
\text { Correlation coefficient (r) }\end{array}$ & $r=0.28$ & $r=-0.21$ & $r=-0.04$ & $\mathrm{r}=0.02$ & $r=0.06$ & $\mathrm{r}=-0.06$ \\
\hline $\begin{array}{c}\text { Years in service } \\
\text { Correlation coefficient }(r)\end{array}$ & $r=0.25$ & $r=-0.20$ & $\mathrm{r}=-0.04$ & $\mathrm{r}=-0.01$ & $r=0.08$ & $r=-0.08$ \\
\hline
\end{tabular}

*Scores for means ranges between 1 - 5 with high scores denoting: Higher efficacy, more fear of offending clients, higher likelihood of blaming victim (for personality or disobedience), higher access to psychiatric support and a higher feeling of conflicting professional roles respectively.

the original system support scale also loaded under the same factor (i.e. having access to social workers). The remaining two items initially belonging to the system support scale (i.e. having access to mental health workers) now formed a new distinct subscale reflecting support from mental health services (i.e. psychiatric support). The splitting of the support network scale into two distinct scales is at odds with results from Nigeria (John \& Lawoko, 2011) and USA (Maiuro, Vitaliano, Sugg, Thompson, Rivara, \& Thompson, 2000). That the Swedish sample identified mental support as a distinct aspect of IPV management and support from social worker as a component of self-efficacy, unlike their peers in the USA and Nigeria could be reflecting contextual issues related to service provision in the different context. Psychiatric care in Nigeria for example is an integrated part of the healthcare service and is usually one of the departments of care at most hospitals. Thus, the Nigerian sample may have viewed a support network to which to refer clients as one component, irrespective of whether such support was from mental healthcare providers or social workers. At Södersjukhuset, the current study setting, on the other hand, a psychiatric care unit is lacking. Therefore any mental health referrals have to be external. It is on these grounds perhaps, that the Swedish respondents may have identified mental services and social services as two distinct aspects related with readiness to screen.

The original scale reflecting a victim blame component was in this study split into two components; "Victim personality/traits" which assigns the occurrence of IPV to individual factors related to the victims personality and voluntary submission to abuse and the other, "Victim disobedience", which assigns the occurrence of abuse to women's divergence from normative societal expectations related to gender. It seems therefore that the Swedish sample were able to acknowledge individual related and societal related aspects of victim blame as distinct aspects affecting readiness to screen, unlike their peers elsewhere (John \& Lawoko, 2011; Maiuro, Vitaliano, Sugg, Thompson, Rivara, \& Thompson, 2000). Likewise, items that in other context (John \& Lawoko, 2011; Maiuro, Vitaliano, Sugg, Thompson, Rivara, \& Thompson, 2000) formed a professional role resistance/fear of offending clients scale, were in this work split into two distinct factors reflecting a professional role resistance and a fear of offending clients scale. Overall therefore, the discrepancy observed between the Swedish and other samples in this regard (i.e. splitting of the original scales) in may be a result of structural differences in availability of services (e.g. social and mental support) at the different settings.

The correlations between the emerging scales were consistent with theory (i.e. significant for scales where significance was expected and non-significant for scales where non-significance was expected). For instance, there is no theoretical or logical support for an association between staffs' blaming attitude towards victim and staffs' self-efficacy. Likewise, there is no logic to explain an association between staffs' access to psychiatric support and their fear of offending clients. Accordingly, no significant correlations were observed between these readiness indicators. On the other hand, significant correlation would be expected (and were observed) between the attitude scales that assign blame to the victim for either personality reason and/or breaking of social norms (i.e. victim personality vs victim disobedience). The significant correlations were however not too high to suspect that the concepts measured a uni-demensional construct. As such, the significant bivariate correlations were an indication that the emerging factors though 
related, represented distinct aspects of readiness to screen for IPV.

Concurrent validity of the shortened DVHSS survey was largely confirmed. Corroborating our hypothesis (i.e. women may be more sympathetic towards abuse of fellow women), together with previous findings from other societal contexts (John, Lawoko, Svanström, \& Mohammed, 2010), female health workers were less likely to perceive conflicting professional roles in relation to IPV inquiries, and to endorse that victims of IPV are to blame for abuse owing to their personality or breaking of gender norms. Similarly, the hypothesis linking readiness to screen to experience was confirmed in our data. Older and more experienced care providers perceived a higher efficacy in handling IPV against women and were less fearful of offending clients through IPV inquiry. That midwives perceived a lower self-efficacy in probing for IPV than other staff cadres is difficult to reconcile based only on this data, but could be a reflection of differences in factors embedded in the training of respective cadre. Further research is warranted to assess training content. Similarly, ambulatory personal appeared less prepared to screen for IPV, were more fearful of offending clients and more likely to perceive that victim disobedience was the cause of IPV than peers in other departments. Overall, the variation in readiness to screen by demographic and occupational characteristics of participants observed in this study is evidence of the concurrent validity of the DVHSS.

The current study assessed the usefulness of an already existing instrument (developed in the USA) in the Swedish context and found the instrument applicable based on its structural validity. However, the item pool used in this study may not be exhaustive of challenges to screening for IPV in the Swedish context. Qualitative studies could reveal additional challenges to screening specific to this context.

A potential weakness of this study concerns the exclusion of certain items in the study. The items in the original scale that concerned IPV inquiry from the perpetrator were dropped from this study. This was because organisation studied intends to introduce screening for IPV predominantly among female clients. An inclusion of these items may have grossly weakened the validity indicators used in this study as participants in the organisation may have failed to identify with these items. Nonetheless, the potential usefulness of involving the perpetrator in IPV prevention need not be overlooked. While it could be assumed that inquiring of IPV perpetration of the perpetrator himself could jeopardize the safety of the healthcare provider and increase victimization of the client, the importance of staff training in improving readiness to inquire of IPV from both victims and perpetrators has been evidenced. Internet-based education, teaching problem-solving skills, was shown to improve physician confidence in domestic violence inquiry among their patients, even in areas that involved probing of domestic violence from the perpetrator (Harris, Kutob, Surprenant, Maiuro, \& Delate, 2002). Similar results have been reported among care professionals who attended extensive on location training on domestic violence screening (Thompson, Rivara, Thompson et al., 2000). Thus comprehensively screening for IPV (i.e. of both victim and perpetrator) in Swedish healthcare should be considered following specific staff training in the matter.

In conclusion, the shortened version of the Domestic Violence Healthcare Provider Survey Scales (DVHPSS) exhibited good factorial stability, internal consistency and concurrent validity. Though none of the items were eliminated through our stringent screening process, the Swedish sample identified a more detailed breakdown of the initial underlying concepts, suggesting that some of the original scales may not in the Swedish healthcare context be measuring a uni-dimensional construct. Thus, to improve the structural validity of the DVHSS in assessment of Swedish careproviders we recommend that items be scored in accordance with the scales identified in this study.

\section{Acknowledgements}

We are most grateful to Centrum För Vårdvetenskap, Karolinska Institutet for funding this study.

\section{REFERENCES}

Aimakhu, C. O., Olayemi, O., Iwe, C. A., Oluyemi, F. A., Ojoko, I. E., Shoretire, K. A., Adeniji, R. A., \& Aimakhu, V. E. (2004). Current causes and management of violence against women in Nigeria. Journal of Obstetrics \& Gynaecology, 24, 58-63. doi:10.1080/01443610310001620314

Altman, D. G. (1991). Practical statistics for medical research. London: Chapman \& Hall.

Altman, D. G. (1982). How large a sample? In S. M. Gore, \& D. G. Altman (Eds.), Statistics in practice. London: British Medical Association.

Brottsförebygande Rådet (BRÅ) (2009). Våld mot kvinnor och män $i$ nära relationer: Våldets karaktär och offrets erfarenhet av kontakter och rättsväsendet. BRÅ rapport 2009:12.

Carroll, J. B. (1957). Biquartimin criterion for rotation to oblique simple structure in factor analysis. Science, 126, 1114-1115.

doi:10.1126/science.126.3283.1114

Cohen, J. (1988). Statistical power analysis for behavioral sciences (2nd ed.). Hillsdale: Lawrence Erlbaum Associates.

Cronbach, L. J., \& Meehl, P. C. (1955). Construct validity in psychological tests. Psychological Bulletin, 52, 281-302. doi:10.1037/h0040957

Erikson, M. J., Hill, T. D., \& Siegal, R. M. (2001). Barriers to domestic violence screening in the padiatric setting. Pediatrics, 108, 98-102. doi:10.1542/peds.108.1.98

Fawole, O. I., Aderonmu, A. L., \& Fawole, A. O. (2005). Intimate partner abuse: Wife beating among civil servants in Ibadan, Nigeria. African Journal of Reproductive Health, 9, 54-64. doi:10.2307/3583462

Feldhaus, K. M., Kozio-Mclain, J., Amsbury, H. L., Norton, I. M., Lowenstein, S. R., \& Abbott, J. T. (1997). Accuracy of 3 brief screening questions for detecting partner violence in the emergency department. Journal of the American Medical Association, 277, 1357-1361. doi:10.1001/jama.1997.03540410035027

Field, A. E., Aneja, P., \& Rosner, B. (2007). The validity of self-reported weight change among adolescents and young adults. Obesity, 15, 2357-2367. doi:10.1038/oby.2007.279

Garcia-Morena, C., Jansen, H., Ellsberg, M., Heise, L., \& Watts, C. (2005). WHO multi-country study on women's health and domestic violence against women: Initial results prevalence, health outcomes and women's responses. Geneva: WHO.

Golding, J. (1999). Intimate partner violence as a risk factor for mental disorders: A meta-analysis. Journal of Family Violence, 14, 99-132. doi:10.1023/A:1022079418229

Harris, J. M., Kutob, R. M., Surprenant, Z. J., Maiuro, R. D., \& Delate, T. A. (2002). Can internet-based education improve physician confidence in dealing with domestic violence? Family Medicine, 34, 287-292.

Heise, L., \& Garcia-Moreno, C. (2002). Violence by intimate partners. In: E. Krug, L. L. Dahlberg, J. A. Mercy et al. (Eds.), World report on violence and health. Geneva: WHO.

John, I. A., Lawoko, S., Svanström, L., \& Mohammed, A. Z. (2010). Health care providers readiness to screen for intimate partner vio- 
lence in Northern Nigeria. Viol Vict., 25, 689-704. doi:10.1891/0886-6708.25.5.689

John, I. A., \& Lawoko, S. (2010). Assessment of the structural validity of the domestic violence healthcare providers' survey questionnaire: Using a Nigerian sample. Journal of Injury and Violence Research, 2, 75-83. doi:10.5249/jivr.v2i2.41

Kishor, S., \& Johnson, K. (2004). Profiling violence: A multi-country study. Measures DHS, ORC Marco, 53-63.

Koenig, M. A., Ahmed, S., Hossain, M. B., \& Khorshed, A. B. (2003). Women's status and domestic violence in rural Bangladesh: Individual and community-level effects. Demography, 40, 269-288. doi:10.1353/dem.2003.0014

Koss, M. (1990). The women's mental health research agenda: Violence against women. American Psychologist, 45, 374-380. doi:10.1037/0003-066X.45.3.374

Maiuro, R. D., Vitaliano, P. P., Sugg, N. K., Thompson, D. C., Rivara, F. P., \& Thompson, R. S. (2000). Development of a health care provider survey for domestic violence: Psychometric properties. American Journal of Preventive Medicine, 19, 245-252. doi:10.1016/S0749-3797(00)00230-0

McFarlane, J., Parker, B., Soeken, K., \& Bullock, L. (1992) Assessing for abuse during pregnancy. Severity and frequency of injuries and associated entry into prenatal care. Journal of the American Medical Association, 267, 3176-3178. doi:10.1001/jama.1992.03480230068030

Nunnaly, J. (1978). Psychometric theory. New York: McGraw-Hill.

Petersen, R., Gazmararian, J., \& Clark, K. (2001). Partner violence. Implications for health and community settings. Women's Health Issues, 11, 116-125. doi:10.1016/S1049-3867(00)00093-1

Rodríguez, M. A., Bauer, H. M., McLoughlin, E., \& Grumbach, K. (1999). Screening and Intervention for intimate partner abuse: Prac- tices and attitudes of primary care physicians. Journal of the American Medical Association, 282, 468-474. doi:10.1001/jama.282.5.468 Roelens, K., Verstraelen, H., Van Egmond, K., \& Temmerman, M. (2006). A knowledge, attitudes and practice survey among obstetrician-gynaecologists on intimate partner violence in Flanders, Belgium. BMC Public Health, 6, 238. doi:10.1186/1471-2458-6-238

Short, L. M., Alpert, E., Harris, J. M., \& Surprenant, Z. J. (2006). A tool for measuring physician readiness to manage intimate partner violence. American Journal of Preventive Medicine, 30, 173-180. doi:10.1016/j.amepre.2005.10.009

Sohal, H., Eldridge, S., \& Feder, G. (2007). The sensitivity and specificity of four questions (HARK) to identify intimate partner violence: A diagnostic accuracy study in general practice, BMC Family Practice, 8, 49. doi:10.1186/147-2296-8-49

Streiner, D. L., \& Norman, G. R. (1989). Health measurement scales a practical guide to their development and use. New York: Oxford University Press, Inc.

Thompson, R. S., Rivara, F. P., Thompson, D. C. et al. (2000). Identification and management of domestic violence-A randomized trial. American Journal of Preventive Medicine, 19, 253-263. doi:10.1016/S0749-3797(00)00231-2

Thorndike, R. M., Cunningham, G. K., Thorndike, R. K., \& Hagen, E. P. (1991). Measurement and evaluation in psychology and education (5th ed.). New York: Macmillan.

Tjaden, P., \& Thoennes, N. (2000) Extent, nature, and consequences of intimate partner violence: Findings from the national violence against women survey. Washington DC: Department of Justice (US).

Tolman, R., \& Rosen, D. (2001) Domestic violence in the lives of women receiving welfare. Violence against Women, 7, 141-158.

World Health Organization (2005). WHO multi-country study on women's health and domestic violence against women. Geneva: WHO. 